\title{
FOTOGRAFIA COMO DISPOSITIVO DA MEMÓRIA INSTITUCIONAL
}

\author{
Carla Beatriz Marques Felipe ${ }^{1}$ \\ Universidade Federal do Rio de Janeiro \\ felipecarla12@gmail.com \\ Fabio Assis Pinho ${ }^{2}$ \\ Universidade Federal de Pernambuco \\ fabiopinho@ufpe.br
}

\begin{abstract}
Resumo
Este trabalho aborda a questão da fotografia como dispositivo para a memória institucional e, dessa forma, apresenta conceitos do que vem a ser memória e memória institucional. Nesse sentido, a pesquisa descreve a fotografia como documento, em consequência, explica a importância e a relação da fotografia como um dispositivo para a memória. A pesquisa caracterizou-se como bibliográfica e o levantamento bibliográfico foi realizado na base BRAPCI, com o objetivo geral de demonstrar a fotografia como um dispositivo para a memória institucional. Os resultados elucidaram a relação entre fotografia e memória, destacando a primeira enquanto um dispositivo de memória institucional.
\end{abstract}

Palavras-chave: Memória. Memória institucional. Fotografia.

\section{PHOTOGRAPHY AS AN INSTITUTIONAL MEMORY DEVICE}

\begin{abstract}
This paper approaches the issue of photography as a device for institutional memory and, in this way, presents concepts of what becomes memory and institutional memory. In this sense, the research describes photography as a document, consequently explains the importance and the relation of photography as a device for memory. The research was characterized as bibliographical and the bibliographic survey was carried out at the BRAPCI database, with the general objective of demonstrating photography as a device for institutional memory. The results elucidated the relationship between photography and memory, highlighting the first as an institutional memory device.
\end{abstract}

Keywords: Memory. Institutional memory. Photography.

\section{INTRODUÇÃO}

O presente e o passado sempre foram objetos de interesse para a humanidade. O mesmo fascínio que levou o ser humano a registrar seu cotidiano desde os primórdios de sua história foi o que impulsionou a conservar suas lembranças. E as lembranças do que se viveu, sentiu no

\footnotetext{
${ }^{1}$ Mestre em Ciência da Informação pela UFPE. Bacharel em Biblioteconomia pela UFRN. Professora Assistente na UFRJ.

2 Doutor e Mestre em Ciência da Informação pela UNESP. Bacharel em Biblioteconomia e Ciência da Informação pela UFSCar. Professor no Programa de Pós-Graduação em Ciência da Informação (Mestrado e Doutorado Acadêmicos) da UFPE.
}

\section{(c) (i) ()}


passado fazem com que cada pessoa seja única. A capacidade de guardar lembranças foi denominada memória. Entendida como um fenômeno social é uma função psíquica, a memória é propriedade de conservar biologicamente certas informações e elementos, sobre fatos vivenciados. A memória é uma aptidão natural do homem e essa aptidão foi auxiliada com registros documentais como, por exemplo, a fotografia.

A palavra fotografia é originária do grego phôs, que significa luz. Para Rodrigues (2007, 69), "é o ato de escrever com luz" e, nesse sentido, presume-se que é a ação de gravar imagens por meios químicos. A associação da fotografia com a memória é um dos aspectos mais compreensíveis de seu uso e, por isso, é notório que ao se deparar com uma fotografia essa remeta a recordações.

Quando se observa uma fotografia se está propenso a criar narrativas sobre algo, rememorar fatos e ter certeza de que algo foi realmente vivido. A passagem do tempo é legitimada quando se observa. Segundo Azevedo Netto (2007, p. 3), "a memória está representada em suportes informacionais distintos". Ela é uma fonte de informação e um documento com várias funções, desde a sua criação até os dias atuais, tornando-se em um meio no qual o homem encontrou para guardar sua memória. Sob essa perspectiva, a fotografia estimula a lembrança. Como a vida não para, nem o tempo, o que permanece registrado é o instante, que não ocorrerá mais. E ao se encontrar com o instante congelado, se está propenso a lembrar de alguma emoção.

A preservação e disseminação da memória é algo que não pode ser ignorado, não só pelo o indivíduo quanto grupos sociais e dentro das instituições. Assim surge a memória institucional, incumbida de manter e propagar os fatos que ocorrem durante todo o trajeto das instituições. Por meio dos documentos produzidos ao longo da trajetória de cada instituição que se tem acesso a sua memória. São os documentos e o acesso a eles que asseguram a preservação da memória institucional. Assim, os indivíduos que fizeram parte da história das instituições também são meios de acesso à memória institucional. No que tange à formação de acervos sobre memória institucional, esses são compostos pelos mais diversos tipos de documentos, dentre eles a fotografia.

Por conta disso, o objetivo geral foi demonstrar a fotografia como um dispositivo para a memória institucional. Na perspectiva de alcançá-lo, os objetivos específicos foram de relatar a compreensão sobre a memória institucional e apresentar a fotografia como dispositivo para a preservação dessa memória. Por isso, essa pesquisa foi caracterizada como bibliográfica e a revisão de literatura foi realizada na base de dados BRAPCI (Acervo de Publicações Brasileiras em Ciência da Informação) para verticalizar a temática no âmbito da Ciência da Informação. A 
análise do resultado da busca foi feita com a leitura dos artigos, com intuito de identificar conceitos e menções sobre memória institucional e fotografia.

\section{MEMÓRIA}

A memória permite a assimilação das experiências, da vivência do indivíduo, mesmo que inconscientemente, é portadora de emoções. Fornece informação para a compreensão do eu. Sobre o passado, Bergson (2006, p. 47) afirma que é algo que segue o ser humano a todo instante, por isso, o autor esclarece que "o que sentimos, pensamos, quisemos desde nossa primeira infância está aí, debruçado sobre o presente”. É em contato com a rememoração do passado que se adquire novos sentidos para atos presentes e futuros. Dessa maneira, se pode comparar o passado e o presente e a memória se torna algo fundamental para o futuro.

Por intermédio da rememoração do passado, pode se ter um auxilio em relação a problemas futuros. A memória não é algo estático, pois é no presente que encontra significado. As lembranças estão em constante movimento, sobretudo, quando os suportes e ambientes entram em contato com o indivíduo. Com a memória, é permitido a reconstrução, renovação das convicções de hoje, com base em experiências passadas.

Memória é a faculdade que acondiciona informações de caráter ligadas ao individual e ao coletivo. Só é acionada quando se depara com algo que traz lembranças, lugares, pessoas. E essa memória é compartilhada por um determinado grupo, pode ser na igreja, na escola, na universidade, no próprio bairro ou em outros. Para Pollak (1992), a memória é algo que é formado no coletivo e passa por constates mudanças. Assim, ao longo da vida do indivíduo, ao viver os mais variados acontecimentos, a sua memória muda e está em constante construção. Pollak (1992) apresenta os elementos que constituem a memória, seja ela individual ou coletiva. Ao entrar em contato com esses elementos, o indivíduo ou o grupo trazem à tona as lembranças. São eles:
a) Acontecimentos vividos pessoalmente;
b) Acontecimentos vividos por tabela;
c) Pessoas e personagens;
d) Lugares.

Os acontecimentos vividos pessoalmente são os fatos em que o indivíduo participa diretamente, pode ser uma dança, um nascimento de um filho. Os acontecimentos por tabela são do grupo, um acontecimento que talvez o indivíduo não tenha participado efetivamente, porém o mesmo pode significar algo para ele, como, por exemplo, as manifestações contra 
governos. Pessoas e personagens são as pessoas que vivenciam os fatos vividos pelos indivíduos, um exemplo seria manifestantes. Lugares da memória são onde os fatos ocorrem, como uma universidade, um hospital. O conjunto constituído por estes elementos formam, segundo Pollak (1992), a memória.

Ainda de acordo com Pollak (1992) parte da memória é herdada. Essa herança não se refere somente à vida física do indivíduo, parte das mutações que ocorrem ao longo da vida do indivíduo, mas, sobretudo, no presente momento. Quando o indivíduo passa por momentos preocupantes na vida, essas preocupações passam a construir um pouco de sua memória, essas preocupações podem ser pessoais ou coletivas.

Original do latim, segundo Anjos et al. (1995, p. 427 apud SILVA; RODRIGUES, 2014, p. 4890), a palavra memória significa "faculdade de reter as ideias, impressões e conhecimentos adquiridos anteriormente. Significa também lembrança, reminiscência, recordação [...]”. Mais especificamente significa relembrar, rememorar. Numa visão geral, é a capacidade de adquirir informação e evoca-la quando necessário o seu uso.

Para Chapouthier (2006, p. 9), "é a capacidade que certos seres vivos têm de armazenar no sistema nervoso, dados ou informações sobre o meio que os cerca, para modificar o próprio comportamento". É preciso ressaltar que a memória não é somente a lembrança por si só dos fatos, mas, sim, o seu significado para o presente do indivíduo ou grupo, colaborando para a composição não só, do presente como também do futuro. E esse significado, dado as lembranças, pode influenciar o seu comportamento, como afirma Chapouthier (2006).

Um dos elementos ligados à memória é a identidade e Pollak (1992, p. 204) a define como:

[...] a imagem que a pessoa adquire ao longo da vida referente a ela própria, a imagem que ela constrói e apresenta aos outros e a si própria, para acreditar na sua própria representação, mas também para ser percebida de maneira que como quer ser percebida pelos outros.

A identidade é o que forma a personalidade tanto do indivíduo quanto do grupo. Não é algo estático, está em constante transformação. A identidade tem sua referência na memória, nas atitudes, vivências e nos outros. Determina o comportamento com relação a si e aos outros. A identidade é o elemento por meio do qual se reconhece e diferencia o indivíduo. Apresenta características pertencentes e únicas do indivíduo que estão intimamente ligadas à sua personalidade. É construída por meio da sua relação com a memória. Assim, a identidade torna o indivíduo capaz de se reconhecer, com relação à sua continuidade no perpassar do tempo.

A memória é fundamental para a sociedade, pois a cultura só pode ser vivenciada, porque a memória permite que sejam rememorados os fatos e assim a construção da identidade. 
É através da memória que se produzem os hábitos e costumes através das experiências vividas, e isso é fundamental para a formação dos grupos sociais. A memória é imprescindível na autoafirmação do indivíduo diante de suas conviç̧ões relacionadas aos seus grupos sociais.

A memória é algo natural, dessa maneira, Holanda (2011, p. 54), “é preponderante perceber que diferentemente da História, a memória não é algo intencionalmente produzido, mas recuperado através de interpretações de relíquias, entendidas como elementos residuais da ação cultural humana". Isso ocorre não só com a memória individual e coletiva, na memória das instituições isso também ocorre. É por meio dos documentos produzidos ao longo da trajetória de cada instituição que se tem acesso a possibilidade de reconstrução da sua memória.

\subsection{MEMÓRIA INSTITUCIONAL}

A memória das instituições (que não são necessariamente instituições de memória) é relevante para a sociedade, pois está ligada à memória social. Tem seus estudos nas áreas de Ciência da Informação, Administração, Arquivologia, Educação e Comunicação. Santos (2014, p. 41) afirma que ao se guardar os mais variados documentos, as instituições formam a sua memória institucional, pois o documento "reflete o conjunto de suas atividades, sua trajetória e sua história". As instituições têm que compreender que essa memória é fundamental para a própria instituição. O conhecimento dos registros dos fatos e pessoas é importante para a reconstrução de sua trajetória perante a sociedade. Assim, documentos e lembranças são constituintes dessa memória.

A memória institucional é um meio de comunicação com a sociedade e como parte integrante dela tem um papel fundamental na formação da memória social. Sob esse aspecto Costa (1997, p. 145) relata que:

[...] a memória é um elemento primordial no funcionamento das instituições. É através da memória que as instituições se reproduzem no seio da sociedade, retendo apenas as informações que interessam ao seu funcionamento. Há um processo seletivo que se desenvolve segundo regras instituídas e que variam de instituição para instituição. Tendo em vista que as instituições funcionam em rede no campo social, o limite de uma instituição é outra instituição.

Por meio da memória institucional, se entra em contato com a história das práticas da instituição, do que foi instituído. Ao se fortalecer a identidade de uma instituição, essa tem a possiblidade de originar e gerar conhecimento. A partir da memória, se pode planejar as atividades futuras a fim de não perder sua identidade. Ao se gerar conhecimento, nos mais variados âmbitos da sociedade, as instituições geram regras de convivência. Segundo Oliveira 
(2012, p.49), "essas convivências, formalizadas ou não, formam o conjunto de experiências e de práticas que por sua vez, formam a memória da instituição”.

Componente fundamental para as instituições, a memória é a maneira como a instituição se apresenta à sociedade a qual pertence e como se relaciona com seu público. Ao se conservarem informações pertinentes ao seu funcionamento, a memória está em contínuo desenvolvimento, visto que as instituições estão sempre em movimento. Desse modo, Molina e Santos $(2014$, p. 11) relata que "a MI (sic), mesmo ainda não realizando todas as suas premissas na prática, é reconhecida por muitos devido ao seu potencial de agregar valor aos negócios, aos relacionamentos e à reputação das instituições”.

As buscas por informações constituintes de sua memória podem ocorrer dentro e fora das instituições. A memória institucional será desenvolvida de acordo com as características da instituição o que torna um processo seletivo. Nesse contexto, a memória institucional produz informação para a inovação. Com isso, é possível o aperfeiçoamento das próprias atividades da instituição. Isso só é possível se essa memória estiver organizada em suportes práticos, como documentos. Pode até se basear na memória oral, porém tem que se registrar de forma escrita, assim se garante a sua preservação e gerenciamento. Esses documentos garantem a perpetuação da memória. Para isso, Molina e Santos (2014, p. 10) argumentam que:

\section{[...] um acervo de memória pode ser constituído por documentos que possibilitam, [...] após a identificação dos tipos documentais, o estabelecimento da tipologia documental, que proporciona o conhecimento da tramitação que o documento percorre dentro de uma organização, propiciando rápido acesso, recuperação e uso, por parte de quem dele necessita, acarretando o aumento da eficiência e eficácia organizacional. Esta organização documental é imprescindível a estruturação da memória institucional/organizacional.}

São os documentos que garantem a segurança do registro da memória institucional, surgem para a contribuição na preservação das recordações. Porém, a memória institucional não é composta somente por documentos. O indivíduo que trabalhou na instituição e lhe serviu de alguma maneira, retém em si a memória institucional. Cada indivíduo possui o seu ponto de vista e se torna peça fundamental para a reconstrução da memória institucional. Essa visão dos indivíduos garante um olhar generoso sobra a história da instituição.

Ao se encontrar com a documentação, não são somente as atividades que serão melhoradas, mas também a permissão para situar a instituição no espaço e tempo ao qual pertence. Com o conhecimento adquirido em relação à instituição, é possível a compreensão das transformações vividas por ela, tanto burocráticas quanto administrativas. Nesse sentido, a memória institucional proporciona a percepção da instituição no todo e compreende a sua identidade. Pode ocorrer que, com o passar do tempo, a identidade da instituição passe a ser 
questionada ou venha ocorrer a perda de suas características. É por meio da memória institucional que se consegue responder a esses questionamentos e se consegue unir todos os componentes para a formação dessa identidade, pessoas, fatos e documentos.

É na área da Comunicação em que se encontram alguns estudos sobre a importância da criação de programas de memória institucional. Esse pensamento está referendado na ideia de que ocorrem perdas nas histórias das instituições por falta de uma política de reconhecimento dessa história. Costa (1995, p. 45-51) já defendia a criação de políticas de meio de organização da memória institucional, a saber:

[...] acreditamos ser fundamental, para o desenvolvimento da memória institucional, a definição de Caminhos (métodos, políticas, meios adequados, etc.) a serem percorridos tendo por objetivo a sua organização. Tais caminhos deveriam ser fundados numa política de memória voltada para ação. Tal política visa alcançar dois objetivos fundamentais: 1) organizar o acervo histórico (bibliográfico, arquivístico e museológico, etc.) de modo a preservar as informações que as instituições e seus agentes produzem; 2) divulgar (transmitir, disseminar) a memória institucional através de ações específicas (programas, projetos) não apenas no interior da(s) própria(s) instituição(ões), mas também no âmbito das sociedades nas quais se inserem. E esta divulgação precisa ser feita através de programas comprometidos com a memória histórica e não nos estreitos limites da história oficial discriminatória.

É no contexto das políticas e programas de construção da memória institucional que se reconhece a importância dos documentos para a instituição. Os documentos carregam as informações necessárias para o reconhecimento da memória e se tornam instrumentos nessa construção. Partindo desse princípio de que a memória institucional é constituída não só pelas pessoas, mas pela junção dessas com os documentos, as fotografias são documentos e constituem os acervos das instituições. Cabe dizer, portanto, que a fotografia pode ser um dispositivo de memória institucional.

\section{FOTOGRAFIA COMO DISPOSITIVO DA MEMÓRIA INSTITUCIONAL}

Toda fotografia é objeto do passado, pois cada momento vivenciado não volta mais e, nesse sentido, mesmo que frequentemos um lugar várias vezes ao longo da vida, nenhuma visita será igual a outra. Sobre esse aspecto, Kossoy (1998, p. 44) relata que, "a fotografia funciona em nossas mentes como uma espécie de passado preservado, lembrança imutável de certo momento e situação, de uma certa luz, de um determinado tema, absolutamente congelado contra a marca do tempo". As emoções que se vivencia podem ser esquecidas e, ao se observar uma fotografia, podem ser despertadas, pois permanecem guardadas, esperando apenas algo que faça com que sejam lembradas. 
Nesse contexto, Le Goff (2003) afirma que a fotografia revolucionou a memória. Isso porque o autor considera a fotografia algo preciso e possuidora de verdade, que nunca se pode alcançar com nenhum outro tipo de representação imagética, além do que permite a conservação da memória do tempo e evolução cronológica. A fotografia torna-se um objeto de preservação da identidade.

A fotografia fornece informações para que o passado seja atualizado e reutilizado no presente. Permite também um melhor entendimento do que se passou na história, como guerras, desastres naturais. Ao se deparar com fotografias desses acontecimentos, se pode ver os detalhes, que muitas vezes os textos não seriam capazes de narrar. É o conteúdo, a imagem congelada, uma cópia fiel que a torna mecanismo da memória individual, coletiva e social. A fotografia toca cada um à sua maneira, é objeto de construção social, mediação cultural e fonte histórica

É no contexto das mudanças sociais que se deve preservar a memória das instituições. Preservar o que passou para construir um futuro com identidade. Nesse sentido, as fotografias servem como documento para auxiliar na construção da memória institucional, juntamente com os outros documentos e com a participação dos membros que constituem a instituição. No que tange a isso, é possível observar que, além das instituições que são reconhecidas como instituições de memória, mais outras guardam cada vez mais fotografias em seus acervos, como parte constituinte de sua memória

Em uma pesquisa realizada no Rio Grande do Sul sobre programas de memória institucional, foi constatado que as instituições se utilizam das fotografias para documentar a sua memória. A pesquisa realizada por Moura e Souza (2010) objetivou compreender a comunicação institucional através da dos programas de memória. Foi realizado um estudo com 23 instituições dos mais variados segmentos. Uma das perguntas elaboradas para a investigação foi sobre quais os itens presentes nos programas de memória institucional. No estudo, foram dadas opções sobre a documentação, entre elas estava a fotografia. Todas as 23 instituições afirmaram que usam a fotografia em seus acervos, constituindo o único documento utilizado em todas essas instituições. Os documentos digitais eram usados apenas por 15 instituições, os impressos por 22 .

Para Manini (2011, p. 80), a fotografia é memória nos mais variados aspectos da sociedade, inclusive na memória institucional; "na fotografia doméstica, é a memória familiar; na fotografia do mundo do trabalho, é a memória institucional; no fotojornalismo, é a memória social e política; na fotografia documental, é a memória histórica”. Nesse contexto, ao se preservar fotografias nas instituições, temos a capacidade de entrar em contato com a sua 
memória. Isso porque, como foi visto, um dos elementos constituintes da memória institucional são os documentos e, entre eles, está a fotografia, as quais atestam visivelmente a memória.

Uma das mais importantes instituições nacionais, o Instituto Brasileiro de Geografia e Estatística - IBGE, possui um acervo fotográfico que retrata sua história. Esse acervo foi criado devido às expedições realizadas pelo instituto Brasil afora, a fim de conhecer a ocupação territorial e os sistemas urbanos do país. As fotografias passaram a ser provas desses estudos e se tornaram documentos fundamentais na trajetória do IBGE. As atividades realizadas pelos pesquisadores do Instituto foram registradas ao longo de sua história e as fotografias serviram como documento para caracterizar as regiões estudadas. Foi por volta da década de 40 que se percebeu a importância de se criar um acervo com as fotografias, visto que cada região estudada possui uma característica diferente da outra. Abrantes (2006, p. 2) afirma que "no sentido de trazer à luz informações essenciais para a memória institucional do IBGE, faz-se necessário enfocar as condições de produção do arquivo fotográfico dessa instituição". Percebendo a importância de sua história, o IBGE possui uma equipe de memória institucional, sob a qual está à responsabilidade pelas fotografias das primeiras expedições e por outras que constituem a trajetória da instituição.

Sobre a fotografia, Valle Gastaminza (2002, não paginado, tradução nossa) diz que "é na perspectiva documental e dimensão testemunhal, que é importante, é o que dá a fotografia sua função de memória individual e coletiva”. Essa perspectiva documental está ligada às memórias institucionais. Como a memória institucional é constituída por documentos e a fotografia se tornou um, e as mais diversas instituições a preservam, pode-se dizer que a fotografia é um documento que serve de base para a construção da memória institucional

É baseado na concepção de que a fotografia é um documento, de fonte de informação e memória, que Brito (2010) fez um estudo sobre o acervo fotográfico do Centro Universitário Franciscano, localizado na Cidade de Santa Maria (RS), a fim de proporcionar conhecimento acerca de sua memória institucional. Brito (2010) apresenta como objetivo geral estudar o acervo, evocar as histórias e memórias da instituição e afirma que as fotografias "apresentam inúmeras perspectivas da vida institucional”.

Para que a pesquisa não fosse muito extensa, a autora utilizou-se do recorte de tempo do ano de 1955, ano de fundação do centro, até o ano de 1980. Para a realização da pesquisa e coleta de informações sobre as fotografias, foi necessário entrevistar as pessoas que fizeram parte da instituição. Assim, ao se entrar em contato com as fotografias e os relatos foi possível construir parte da memória institucional do centro, já que ocorreu um recorte temporal. Ao final do trabalho, Brito (2010, p. 121) chega à conclusão que: 
[...] as lembranças, as memórias, e histórias que podem ser evocadas por meio da consulta do acervo fotográfico da instituição, além de configurarem-se como registros de informações, podem ser traduzidas em registros poéticos que evocam sentimentos, que trazem à tona momentos vividos pelos personagens nelas representadas.

Além de concluir que as fotografias do centro retravam as suas memórias, foi perceptível o quão é importante, para a cidade de Santa Maria, o Centro Universitário Franciscano. Percebeu-se que o centro constitui a memória da cidade, e consequentemente, do Rio Grande do Sul.

Portanto, a memória institucional é elemento na construção da identidade institucional. Foi a essa conclusão que Eggert-Steindel e colaboradores (2013) chegaram ao concluir uma pesquisa sobre as fotografias da Biblioteca Pública de Santa Catarina. Essa instituição é considerada importante para a sociedade catarinense, pois preserva a memória intelectual e cultural do estado. O objetivo da pesquisa foi (re)conhecer uma memória e suas possíveis representações nos itens fotográficos. Nessa perspectiva, Eggert-Steindel e colaboradores (2013, p. 131) afirmam que, a memória está presente nas fotografias e ela auxilia na construção do futuro da instituição:

[...] debruçar-se sobre esse conjunto de itens fotográficos entre as muitas questões que se puderam levantar permite afirmar que as informações fotográficas são possibilidades da guarda de uma memória- documento, não apenas do tempo do passado, mas uma memória para o tempo futuro.

As fotografias retratavam toda a história da instituição, fatos ligados aos usuários, como ações culturais, mudança na arquitetura do prédio que abriga a biblioteca, incremento nas tecnologias de informação e outros tipos de mudança que podem ser percebidos por meio das fotografias.

$\mathrm{Na}$ memória institucional, deve se estar preocupado com a contextualização das fotografias em relação à instituição. Quais fotos foram produzidas pela instituição, se estas têm realmente ligação com a memória, em que momento foram produzidas, qual o acontecimento da trajetória da instituição foi retratado. Para Eggert-Steindel e colaboradores (2013), as fotografias são objetos de memória, que auxiliam na construção da memória institucional. Logo, a identidade da instituição pode ser observada por meio delas. Como foi visto, a fotografia é um dispositivo de memória institucional. Devido à sua capacidade de registrar imageticamente os fatos que marcam as trajetórias das instituições, se faz presente no cotidiano das mesmas, capturando os momentos e pessoas que fazem parte da memória desses lugares. 


\section{CONSIDERAÇÕES FINAIS}

Por meio das fotografias, muitas histórias são contadas, lembranças revividas, lugares que se modificaram ou que não existem mais, podem ser revisitados a qualquer momento. A fotografia possui a capacidade de eternizar os momentos, devido ao seu caráter de representação da realidade. Às vezes, os momentos que são vivenciados não são de tão grande importância para a vida, mas mesmo assim, se registram por meio das fotografias. A memória é transmitida pela fotografia, devido à sua capacidade de fornecer detalhes, que provavelmente se encontravam perdidos nas lembranças. Por meio das fotografias, esses detalhes permanecem vivos.

É perceptível que a fotografia tenha um valor para a memória, não só individual como coletiva. Por meio delas, se recordam fatos que marcaram a vidas das pessoas de alguma maneira. Esses fatos podem ser simples ou acontecimentos de importância mundial, que de alguma forma afetaram a vida do indivíduo.

A fotografia como documento pode servir de instrumento para a reconstrução da memória institucional. A memória institucional é a memória das instituições, não necessariamente de instituições de memória. É constituída não só pelos documentos, mas também pelos indivíduos que fazem parte do seu corpo de trabalho. A junção dos documentos com indivíduo proporciona um melhor entendimento sobre memória institucional. Isso facilita a criação de uma linha do tempo com os fatos constituintes da memória institucional. Quando o indivíduo não se lembra do fato, o documento está presente como prova. E é nesse sentido que se considera a fotografia como um dispositivo para a memória institucional.

Fica claro que as instituições estão cada vez mais preocupadas na preservação e disseminação da sua memória. A memória é difundida pela fotografia por causa da sua capacidade em oferecer detalhes, que não se pode encontrar em nenhum outro tipo de documento. Fica demonstrada a importância da fotografia como dispositivo de memória para as instituições. 


\section{REFERENCIAS}

ABRANTES, Vera Lucia Cortes. Imagens produzidas pelo fotógrafo Tibor Jablonsky: suportes materiais na construção da memória do trabalho no Brasil (1950-1968). In: ENCONTRO REGIONAL DE HISTÓRIA, 12., 2006, Rio de Janeiro. Anais... Rio de Janeiro: ANPUH-RJ, 2006. Disponível em: $<$ www.rj.anpuh.org/.../rj/.../Vera\%20Lucia\%20Cortes\%20Abrantes.pdf $>$. Acesso em: 02 abr. 2018 .

AZEVEDO NETTO, Carlos Xavier. Informação e memória: as relações na pesquisa. Revista História em Reflexão, Dourados, v. 1, n. 2, p.1-20, jul./dez. 2007.

BERGSON, Henri. Memória e vida. São Paulo: Martins Fontes, 2006.

BRITO, Luciana Souza. Histórias e memórias institucionais a parir do acervo fotográfico do Centro Universitário Franciscano (1955-1980). 2010. 256 f. Dissertação (Mestrado Profissional em Patrimônio Cultural) - Programa de Pós-Graduação em Patrimônio Cultural. Rio Grande do Sul, 2010. Disponível em:

<coralx.ufsm.br/tede/tde_busca/arquivo.php?codArquivo=2970>. Acesso em: 10 abr. 2015.

CHAPOUTHIER, Georges. Registros evolutivos. Viver Mente \& Cérebro, São Paulo, n. 2, p. 8-13, jul. 2006.

COSTA, Icléia Thiesen Magalhães. Memória institucional: a construção conceitual numa abordagem teórico-metodológica. 1997. 169 f. Tese (Doutorado em Ciência da Informação) Universidade Federal do Rio de Janeiro, Rio de Janeiro, 1997. Disponível em: <http://tededep.ibict.br/tde_arquivos/1/TDE2008-02-15T15:39:41Z-24/Publico/icleiacosta1997.pdf.>. Acesso em: 23 jun. 2018.

COSTA, Icléia Thiesen Magalhães. Memória institucional: um conceito em definição. Informare - Cadernos do Programa de Pós-Graduação em Ciência de Informação, Rio de Janeiro, v. 1, n. 2, p. 45-51, jul./dez. 1995.

EGGERT-STEINDEL, Gisela et al. Imagens/memórias da Biblioteca Pública de Santa Catarina: uma leitura da memória volátil fixada pela fotografia (1980-2011). Perspectivas em Ciência da Informação, Belo Horizonte, v. 18, n. 4, p. 127-138, out./dez. 2013. Disponível em: <http://www.scielo.br/pdf/pci/v18n4/09.pdf>. Acesso em: 10 abr. 2018.

HOLANDA, Adriana Buarque de. Memória e esquecimento na Ciência da Informação: um estudo exploratório. 2011. 142 f. Dissertação (Mestrado em Ciência da Informação) Universidade Federal de Pernambuco, Recife, 2011.

KOSSOY, Boris. Fotografia e memória: reconstituição por meio da fotografia. In: SAMAIN, Etienne. (Org.). O fotográfico. São Paulo: Hucitec, 1998.

LE GOFF, Jaques. História e memória. 5 ed. Campinas, SP: Editora da Unicamp, 2003.

MANINI, Mirian Paula. Imagem, memória e informação: um tripé para o documento fotográfico. Domínios da Imagem, Londrina, v. 4, n. 8, p.77-88, maio 2011. Disponível em: 
$<$ http://www.uel.br/revistas/dominiosdaimagem/index.php/dominios/article/view/127>. Acesso em: 14 abr. 2018.

MOLINA, Letícia Gorri; SANTOS, Juliana Cardoso. Documento e memória: "Locus de memória institucional. In: COLÓQUIO INTERNACIONAL DA REDE MUSSI, 3., 2014, Salvador. Anais... Salvador: Rede Mussi, 2014. Disponível em:

$<$ http://www.coloquiomussi.ici.ufba.br/>. Acesso em: 28. mar. 2015.

MOURA, Claudia Peixoto; SOUZA, Alina Oliveira de. Memória e comunicação institucional: a construção de relacionamentos com base em acervos. In: CONGRESSO BRASILEIRO DE CIÊNCIAS DA COMUNICAÇÃO, 33., 2010, Caxias do Sul, RS. Anais... Caxias do Sul: INTERCOM, 2010. Disponível em: $<$ http://portal.eusoufamecos.net/memoriae-comunicacao-institucional-a-construcao-derelacionamentos-com-base-em-acervos/ $>$. Acesso em: 20 abr. 2018.

OLIVEIRA, Marlene de. Memória institucional da Associação Brasileira de Educação em Ciência da Informação (ABECIN). 2012. 152 f. Dissertação (Mestrado Profissional em Gestão da Informação) - Universidade Estadual de Londrina, Londrina. 2012. Disponível em: $<$ http://www.uel.br/revistas/uel/index.php/infoprof/article/view/14594>. Acesso em: 28. mar. 2018.

POLLAK, Michael. Memória e identidade social. Estudos Históricos, Rio de Janeiro, v.5, n. 10, p. 200-212, 1992.

RODRIGUES, Ricardo Crisafulli. Análise e tematização da imagem fotográfica. Ciência da Informação, Brasília, v. 36, n. 3, p. 67-76, set./dez. 2007. Disponível em: $<$ http://www.scielo.br/scielo.php?script=sci_arttext\&pid=S0100-19652007000300008>. Acesso em: 02 fev. 2018.

SANTOS, Ana Cláudia de Araújo. Aspectos memoriais existentes nos retratos dos reitores da Universidade do Recife. 2014. 271 f. Dissertação (Mestrado em Ciência da Informação) Universidade Federal de Pernambuco, Recife, 2014.

SILVA, Rubens Alves; RODRIGUES, Vanilza Jacundino. Memória, informação e patrimônio afro-brasileiro em Minas Gerais. In: ENCONTRO NACIONAL DE PESQUISA EM CIÊNCIA DA INFORMAÇÃO, 15., 2014, Belo Horizonte. Anais eletrônicos... Belo Horizonte: ANCIB, 2014. Disponível em: <http://enancib2014.eci.ufmg.br/news/anais-do-Xvenancib-publicados>. Acesso em: 20 jun. 2018.

VALLE GASTAMINZA, Félix del. Estética de la fotografia: dimensión documental de la fotografia. 2002. Disponível em: $<$ http://www.fcif.net/estetica/dimensionfotografia.htm>. Acesso em: 20 jun. 2018. 